\title{
Excess Corticotropin Releasing Hormone-Binding Protein in the Hypothalamic-Pituitary-Adrenal Axis in Transgenic Mice
}

\author{
Heather L. Burrows, ${ }^{\star \ddagger}$ Masaharu Nakajima, ${ }^{\S}$ J. Shonee Lesh,, Ki A. Goosens, \\ Sally A. Camper, ${ }^{\star \ddagger}$ and Audrey F. Seasholtz,,$\|$ \\ *Cellular and Molecular Biology Program, ${ }^{\ddagger}$ Department of Human Genetics, ${ }^{\S}$ Department of Physiology, "Mental Health Research \\ Institute, and "Department of Biological Chemistry, University of Michigan, Ann Arbor, Michigan 48109; and **Second Department of \\ Medicine, Kobe University, Kobe, Japan 650
}

\begin{abstract}
Corticotropin-releasing hormone (CRH) is the primary hypothalamic releasing factor that mediates the mammalian stress response. The CRH-binding protein (CRH-BP) is secreted from corticotropes, the pituitary CRH target cells, suggesting that the CRH-BP may modulate hypothalamicpituitary-adrenal (HPA) axis activity by preventing CRH receptor stimulation. Transgenic mice were generated that constitutively express elevated levels of CRH-BP in the anterior pituitary gland. RNA and protein analyses confirmed the elevation of pituitary CRH-BP. Basal plasma concentrations of corticosterone and adrenocorticotropin hormone (ACTH) are unchanged, and a normal pattern of increased corticosterone and ACTH was observed after restraint stress. However, CRH and vasopressin (AVP) mRNA levels in the transgenic mice are increased by 82 and 35\%, respectively, to compensate for the excess CRH-BP, consistent with the idea that CRH-BP levels are important for homeostasis. The transgenic mice exhibit increased activity in standard behavioral tests, and an altered circadian pattern of food intake which may be due to transgene expression in the brain. Alterations in CRH and AVP in response to elevated pituitary CRH-BP clearly demonstrate that regulation of CRH$\mathrm{BP}$ is important in the function of the HPA axis. (J. Clin. Invest. 1998. 101:1439-1447.) Key words: stress • vasopressin • homeostasis • behavior • locomotion
\end{abstract}

\section{Introduction}

Homeostasis is crucial to living organisms and is one of the major tasks of the endocrine system. One organ that is particularly important in responding to changes in body equilibrium is the anterior pituitary, which serves as the intermediary between the central nervous system (CNS) and the peripheral endocrine organs. The hypothalamus secretes numerous peptide hormones that regulate pituitary function. One of these is corticotropin-releasing hormone $(\mathrm{CRH}),{ }^{1}$ a major regulator of

Address correspondence to Audrey F. Seasholtz, Ph.D., Mental Health Research Institute, University of Michigan, 205 Zina Pitcher Place, Ann Arbor, MI 48109-0720. Phone: 734-936-2072; FAX: 734647-4130; E-mail: aseashol@umich.edu

Received for publication 9 October 1997 and accepted in revised form 2 February 1998.

J. Clin. Invest.

(C) The American Society for Clinical Investigation, Inc. 0021-9738/98/04/1439/09 \$2.00

Volume 101, Number 7, April 1998, 1439-1447

http://www.jci.org the hypothalamic-pituitary-adrenal (HPA) axis. The HPA axis is involved in maintaining body homeostasis, including modulating the stress response. Disruptions in the HPA axis have been observed in many neurologic and psychiatric disorders, including major depression, Alzheimer's disease, eating disorders, and Cushing's syndrome (1). In addition, the function of the HPA axis appears to change during the normal aging process (2). Thus, regulation of the HPA axis is a dynamic process, important for many aspects of health.

A clue to one potential regulator of the HPA axis comes from studies of pregnant women. While human plasma CRH levels are normally undetectable, plasma CRH levels are elevated significantly in late pregnancy due to placental production of CRH. Despite the high levels of CRH, the HPA axis is not activated, and pregnant women do not demonstrate the hypercortisolemia of Cushing's syndrome (3). The high levels of $\mathrm{CRH}$ in maternal plasma are masked by binding to the CRH-binding protein (CRH-BP), a 37-kD secreted glycoprotein produced by human liver and the placenta (4-6). Thus, CRH-BP acts to modulate this peripheral activity of CRH. Although rodents do not express $\mathrm{CRH}$ or $\mathrm{CRH}-\mathrm{BP}$ in the placenta during pregnancy, both humans and rodents produce $\mathrm{CRH}-\mathrm{BP}$ in a subset of pituitary corticotropes and in various regions of the brain where it often colocalizes with sites of $\mathrm{CRH}$ expression or with CRH target cells (7). We hypothesize that CRH-BP acts within the CNS and HPA axis in the same fashion as demonstrated peripherally, to modulate the activity of CRH.

In vitro studies have shown that binding of $\mathrm{CRH}$ by $\mathrm{CRH}-$ $\mathrm{BP}$ results in $\mathrm{CRH}$ inactivation and decreased adrenocorticotropin hormone $(\mathrm{ACTH})$ release $(8,9)$. However, the role that CRH-BP plays in mediating or modulating the actions of central CRH in vivo is not known. Binding proteins for some other factors are very important in modulating the biological effects of their ligands. For example, there are multiple binding proteins for the IGFs produced by the liver in response to pituitary growth hormone stimulation. The IGFs are crucial for prenatal and postnatal growth. The binding proteins have been shown to provide a storage pool of IGF and to increase IGF's serum half-life. In addition, IGF-BPs can either inhibit or potentiate some of the effects of IGF, suggesting that regulation of these binding proteins is an important component of growth control (10).

During the normal stress response, the body increases its production and release of $\mathrm{CRH}$, leading to an increase in

1. Abbreviations used in this paper: $\mathrm{ACTH}$, adrenocorticotropin hormone; $\mathrm{CMV}$, cytomegalovirus; $\mathrm{CRH}$, corticotropin-releasing hormone; CRH-BP, CRH-binding protein; $\alpha$-GSU, glycoprotein hormone $\alpha$-subunit; h, human; LS, lateral septal nucleus; m, mouse; PVN, paraventricular nucleus. 
ACTH production (11). ACTH acts on the adrenal cortex, resulting in increased glucocorticoid production. These glucocorticoids then produce many of the physiological responses that are important for the survival of the individual, including negative feedback on the pituitary and hypothalamus to return the system to homeostasis. Excess CRH leads to many physical changes, including hyperplasia of the zona fasciculata of the adrenal gland. CRH-BP may play a role in blunting this $\mathrm{CRH}$ stimulus. In addition, CRH-BP may be involved in modulating the nonstress levels of CRH which would affect normal development.

To investigate the function of CRH-BP, transgenic mice were generated that constitutively express elevated levels of CRH-BP in the anterior pituitary gland. This was accomplished by expressing the mouse (m) CRH-BP cDNA under the control of the pituitary glycoprotein hormone $\alpha$-subunit ( $\alpha$-GSU) promoter. A 4.6-kb fragment of the m $\alpha$-GSU 5 -flanking sequence directs high levels of transgene expression in adult pituitary gonadotropes and thyrotropes with varying low levels of transgene expression in a few sites within the CNS (12). Developmental analysis revealed that transgene expression is limited to the developing anterior pituitary (13). An advantage of this system is that the $\alpha$-GSU promoter is not regulated by corticosterone levels, and thus expression of the transgene will be unaffected by any alterations in the HPA axis. Although endogenous CRH-BP is produced in the corticotropes of the anterior pituitary (7) rather than the gonadotropes and thyrotropes, CRH-BP is thought to act as a secreted protein. Thus, the transgene product should be highly expressed by the gonadotropes and thyrotropes and secreted into the heterogeneous pituitary, where it will be ready to interact with $\mathrm{CRH}$ in the extracellular regions around the corticotropes. Because the transgene is not expressed in the corticotropes, this model will not investigate any other potential intracellular roles of $\mathrm{CRH}$ BP. It is possible that excess CRH-BP might produce alternate effects if it were expressed in corticotropes. Because CRH-BP expression is high in the anterior pituitary, the site of endocrine action of $\mathrm{CRH}$, this transgenic mouse model tests the role of chronic elevation of secreted CRH-BP particularly in the HPA axis.

\section{Methods}

Plasmid construction. The CRH-BP overexpression plasmid, $\alpha \mathrm{CRH}-$ $\mathrm{BP}$, contains $-5,000$ to $+43 \mathrm{bp}$ of the $\mathrm{m} \alpha$-GSU promoter and $5^{\prime}$-flanking DNA linked to the mCRH-BP cDNA coding sequence $(1.3 \mathrm{~kb})$ and a mouse protamine 1 intron and polyadenylation signal $(0.5 \mathrm{~kb})$. Partial digestion of a $5.0-\mathrm{kb} \mathrm{m} \alpha-\beta$ gal clone (12) with BamHI removed the $\beta$-galactosidase gene and generated an $8.6-\mathrm{kb}$ fragment containing the $5.0-\mathrm{kb} \alpha$-GSU promoter, pnlacF vector, and mouse protamine 1 sequence. A 1.3-kb XmnI/XbaI fragment containing the coding sequence of the mCRH-BP cDNA was isolated from the mCRH-BP cDNA clone 5 (8) and subcloned into the XbaI and XmnI sites in the polylinker of the $\mathrm{pGem} 7 \mathrm{z}$ vector (Promega Corp., Madison, WI) to generate $\mathrm{CRH}-\mathrm{BP} 7 \mathrm{z}$. The 1.3-kb CRH-BP fragment was subsequently excised from $\mathrm{CRH}-\mathrm{BP} 7 \mathrm{z}$ by partial digestion with BamHI. The two BamHI fragments were ligated together to create $\alpha \mathrm{CRH}$ $\mathrm{BP}$. The direction of the CRH-BP insert and the identity of the clone were confirmed by restriction mapping.

The plasmid template for the riboprobe used to detect the transgene and endogenous mRNA by RNase protection, pBPmp1, consists of a 227-bp fragment of $\alpha \mathrm{CRH}-\mathrm{BP}$ containing the junction between the CRH-BP cDNA and the mouse protamine 1 sequence inserted in the pGem-T vector (Promega Corp.). The $\alpha \mathrm{CRH}$-BP fragment was synthesized by PCR amplification using the oligonucleotides 5'-GAG TAT CGT CAG CTG GAG CC-3' and 5'-GCA TCT GCT CCT GCT TTT G-3'. The identity of the clone was confirmed by DNA sequencing of the insert.

Tissue culture and transfection. $\alpha$-TSH and $\alpha \mathrm{T} 3-1$ cells were kindly provided by Dr. Pamela Mellon (University of California, San Diego). The cells were maintained in DME (Life Technologies, Inc., Gaithersburg, MD) supplemented with 5\% FCS and 5\% horse serum (Hyclone, Logan, UT) as described previously $(14,15)$. Cells were plated at $3 \times 10^{5}$ cells $/ 60-\mathrm{mm}$ plate and transfected by calcium phosphate-DNA precipitation with $\alpha \mathrm{CRH}-\mathrm{BP}$ or with cytomegalovirus (CMV) mCRH-BP (8) as a positive control. Untransfected cells were used as negative controls in all experiments. Cells and media were collected $48 \mathrm{~h}$ after transfection. Cell pellets were lysed in $100 \mu \mathrm{l}$ of $0.25 \mathrm{M}$ Tris ( $\mathrm{pH} 7.5), 0.5 \%$ Triton X-100 and centrifuged for $10 \mathrm{~min}$ at $15,000 \mathrm{rpm}$ to remove membranes and cellular debris. Medium from $\alpha \mathrm{CRH}-\mathrm{BP}$-transfected cells was concentrated 10-fold using Centriprep 10 (Amicon, Inc., Beverly, MA) centrifugal concentrators before analysis. $40 \mu \mathrm{l}$ of cell extract or $40 \mu \mathrm{l}$ concentrated ( $\alpha \mathrm{CRH}-\mathrm{BP})$ or unconcentrated (untransfected or CMVmCRH-BP) media was used to determine CRH-BP activity by cross-linking assay.

Generation and maintenance of transgenic mice. The 6.4-kb transgene fragment from $\alpha \mathrm{CRH}-\mathrm{BP}$ was isolated by digestion with KpnI and HindIII, which reduces the $\alpha$-GSU promoter to $4.6 \mathrm{~kb}$. The DNA was isolated by agarose gel electrophoresis and purified with the SpinBind DNA recovery system for agarose gels (FMC Bioproducts, Rockland, ME). The purified DNA was microinjected into $\mathrm{F}_{2}$ zygotes from C57BL/6J $\times$ SJL parents at a concentration of 2-3 ng/ $\mu$ l (16). After overnight incubation, embryos at the two-cell stage were transferred to day 0.5 postcoitum pseudopregnant CD-1 females. Genomic DNA prepared from tail biopsies was screened for the presence of the transgene by PCR assay using the oligonucleotides 5'-TAC CAA GTG CCA TCC AAT CA-3' and 5'-GAG CTC AAA GCA GCG AGG-3'. A PCR assay for $\beta$-globin was used as a positive control for the quality of the genomic DNA sample. The $\beta$-globin primers are 5'-CCA ATC TGC TCA CAC AGG ATA GAG AGG GCA GG-3' and $5^{\prime}$-CCT TGA GGC TGT CCA AGT GAT TCA GGC CAT CG-3'.

Eight transgenic founders were identified from 100 mice. Six lines were established by breeding these founders and their progeny to C57BL/6J mice. Mice were maintained on a 14:10 light/dark schedule, with lights on between 6:00 and 20:00. They were given food (5020 mouse chow, $9 \%$ fat content; Purina Mills, Inc., St. Louis, MO) and water ad libitum. For all studies, transgenic mice were paired with a nontransgenic littermate of the same sex. For each behavioral test, mice were of the same generation $\left(\mathrm{F}_{4}\right.$ or $\left.\mathrm{F}_{5}\right)$ and were between 2 and 4 mo of age. For all protein, RNA, and hormone analysis, mice were housed individually for at least $3 \mathrm{~d}$ before killing. To avoid stressing the animal before killing, quiet was maintained in the animal housing room, and we avoided moving or touching cages until each animal was moved quickly to an adjacent room for rapid bleeding and killing by cervical dislocation. Each animal was handled with clean gloves (17). Blood was collected from each animal to confirm that it was not stressed. Only animals with plasma corticosterone levels $<100 \mathrm{ng} / \mathrm{ml}$ were considered unstressed and included in experiments.

C57BL/6J and C57BL/6J $\times$ SJL mice (The Jackson Laboratory, Bar Harbor, ME) and CD-1 mice (Charles River Laboratories, Wilmington, MA) were bred at the University of Michigan. All procedures using mice were approved by the University of Michigan Committee on Use and Care of Animals. All experiments were conducted in accordance with the principles and procedures outlined in the National Institutes of Health guidelines for the Care and Use of Laboratory Animals.

In situ hybridization. In situ hybridization was performed as described $(18,19)$ except that tissue sections were rinsed in $2 \times \operatorname{SSC}(0.3 \mathrm{M}$ $\mathrm{NaCl}, 0.03 \mathrm{M}$ sodium citrate, $\mathrm{pH}$ 7.3) after fixation. Antisense and sense riboprobes were generated for each transcript analyzed. $\mathrm{CRH}-$ 
BP riboprobes were generated from a 666-bp PvuII fragment of mouse CRH-BP cDNA clone 5 (8), subcloned into the pGem3z vector (Promega Corp.) to create mCRHBP666. CRH riboprobes were synthesized from pGem4zPst578 (19), which contains a 578-bp PstI fragment of the mouse CRH exon II. Arginine vasopressin (AVP) riboprobes were generated from rat AVP exon C (229-bp PstI fragment of the rat AVP exon $\mathrm{C}$ subcloned into pGem4; provided by $\mathrm{S}$. Watson, University of Michigan). The probes were labeled with ${ }^{35}$ S $]$ UTP (DuPont-NEN, Wilmington, DE).

Slides were hybridized overnight in $50 \%$ formamide hybridization buffer containing $1.5 \times 10^{6} \mathrm{cpm}$ of riboprobe in $50 \mu \mathrm{l}$ at $56^{\circ} \mathrm{C}$ in a humidified chamber (20). Posthybridization treatment was as described (18). The final washes were performed in $0.1 \times \mathrm{SSC}$ at $60^{\circ} \mathrm{C}$ for all riboprobes. Sections were dehydrated, air dried, and exposed to Biomax MR autoradiography film (Eastman Kodak Co., Rochester, NY) for 3-10 d. Slides were then dipped in NTB nuclear emulsion (Eastman Kodak Co.) diluted 1:1 in water, exposed for 1-4 wk, developed, and counterstained with cresyl violet (Sigma Chemical Co., St. Louis, MO). There was no signal above background in any sections hybridized with the sense riboprobes.

Assay for CRH-BP activity by cross-linking. The binding of CRHBP to (2- $\left.{ }^{125} \mathrm{I}\right]$ iodohistidyl ${ }^{32}$ ) human CRH (Amersham Corp., Arlington Heights, IL) was analyzed by chemical cross-linking as described previously (8). Mouse pituitaries were lysed in $250 \mu \mathrm{l}$ of $100 \mathrm{mM}$ sodium phosphate ( $\mathrm{pH} 8.0), 50 \mathrm{mM}$ Tris ( $\mathrm{pH} 8.0), 0.5 \%$ Triton X-100, $1 \mathrm{mM}$ PMSF using a 25-gauge needle. Protein concentrations were determined by protein assay (Bio-Rad Laboratories, Hercules, CA). Cross-linking reactions $(100 \mu \mathrm{l})$ contained $550 \mu \mathrm{g}$ pituitary protein (or $40 \mu \mathrm{l}$ cell extract or medium), $60 \mu \mathrm{l}$ of binding buffer (100 mM sodium phosphate [pH 8.6], 0.1\% BSA, $0.01 \%$ sodium azide, $50 \mathrm{mM}$ sodium chloride), and $5 \mathrm{fmol}$ of ${ }^{125} \mathrm{I}-\mathrm{CRH}(2,000-3,000 \mathrm{Ci} / \mathrm{mmol})$. After a 2-h incubation at room temperature, $5 \mu \mathrm{l}$ of $20 \mathrm{mM}$ disuccinimidyl suberate (DSS; Boehringer Mannheim, Indianapolis, IN) was added. After 10-15 min at room temperature, cross-linking reactions were terminated by the addition of $30 \mu$ l cold $5 \times$ loading dye containing $50 \mathrm{mM}$ Tris (pH 6.8), 35\% glycerol, $30 \%$ $\beta$-mercaptoethanol, $2 \%$ SDS, $0.1 \%$ bromophenol blue. Samples were boiled for $10 \mathrm{~min}$ and analyzed on $10 \%$ SDS-polyacrylamide gels. Gels were dried and exposed to XAR-5 film (Eastman Kodak Co.).

Blood collection and RIA analysis. Plasma for corticosterone and ACTH analysis was collected by rapid retroorbital phlebotomy into heparinized capillary tubes (corticosterone) or siliconized Pasteur pipettes $(\mathrm{ACTH})$ with time from first handling the animal to completion of bleed not exceeding $45 \mathrm{~s}$. Blood was placed immediately in iced Eppendorf tubes containing EDTA. Plasma was separated by centrifugation at $6,000 \mathrm{rpm}$ and stored in aliquots at $-80^{\circ} \mathrm{C}$ until assayed. All blood sampling was performed between 10:00 and 12:00 on mice which had been housed individually for at least $3 \mathrm{~d}$.

Plasma corticosterone was determined as instructed using the Coat-A-Count rat corticosterone RIA kit (DPC, Los Angeles, CA). Plasma ACTH was determined using the human ACTH 130T kit (Nichols Institute Diagnostics, San Juan Capistrano, CA). The assay was performed as instructed except that $50 \mu l$ of sample was used instead of $200 \mu \mathrm{l}$. The negative control provided in the kit was used to dilute the sample to $200 \mu$ l. All values were corrected for this dilution. Samples were performed in duplicate when possible.

Acute stress analysis. Mice were housed individually for at least $3 \mathrm{~d}$ before stress experiments. Animals were stressed by restraint in a custom Plexiglas apparatus. This restraint device consists of a $9 \times 12$ $\mathrm{cm}$ piece of flexible Teflon attached to a $9 \times 3 \mathrm{~cm}$ platform with Plexiglas ends with a tail slot and air holes. The Teflon is wrapped snugly around the mouse and fastened with Velcro straps. The mice were stressed for $30 \mathrm{~min}$ and then returned to their home cages. Since blood collection was as stressful as restraint, we determined that only one sample could be collected from each animal (our unpublished observations). With practice, basal levels of corticosterone assayed before restraint were consistently $<75 \mathrm{ng} / \mathrm{ml}$, so it was unnecessary to take blood samples to determine both the basal level and the level in response to stress from each individual mouse. Each mouse was bled once for a single time point at various times after the initiation of stress.

Quantitation of AVP and CRH signal. Brains from unstressed mice were frozen in 2-methyl-butane cooled to -30 to $-40^{\circ} \mathrm{C}$ on dry ice and embedded in OCT (Miles Laboratories, Inc., Elkhart, IN) tissue-embedding medium. The brains were sectioned coronally using a cryostat (Bright Instrument Co., Ltd., Huntingdon, UK) into $18-\mu \mathrm{m}$-thick sections and mounted at 1 section/slide onto polyL-lysine-coated slides. Every seventh slide was stained with cresyl violet (Sigma Chemical Co.) to determine orientation and location. In situ hybridization with a $\mathrm{CRH}$ riboprobe was performed on every second slide throughout the paraventricular nucleus (PVN). Adjacent slides were analyzed for AVP expression by in situ hybridization. All sections were assayed in the same experiment to control for experimental variation. Slides were exposed to autoradiography film for 7 (AVP) or $3 \mathrm{~d}(\mathrm{CRH})$. AVP riboprobes had a much lower specific activity than CRH riboprobes and therefore required longer than normal exposure times. Autoradiography films were scanned and analyzed using NIH Image 1.21. The most intense signals were confirmed to be within the linear range of the film. Each hemisphere of the brain was quantitated separately, and the integrated signal (average signal $\times$ area of signal) was calculated. The three-dimensional structure of the PVN varies from rostral to caudal. To control for this variability, five slides spanning the section containing the highest integrated signal intensity were compared for each animal.

Behavioral testing. Male mice were housed individually in a quiet room for 3-5 d before the start of the experiment. Cages were encoded, and the investigator performing the experiments and analysis was unaware of the genotypes of the animals. Testing was performed between 10:00 and 14:00 or between 16:00 and 18:00 in the same room. Open field performance was measured for $5 \mathrm{~min}$ in a $40 \times 20 \times 18$ $\mathrm{cm}$ plastic cage with a gridded floor for 3-5 consecutive days as described (21). A different cage was used for each animal. This was followed by $1 \mathrm{~d}$ of elevated plus-maze testing $(21,22)$. The elevated plus-maze consists of four arms $(27 \times 6 \mathrm{~cm})$ arranged in a plus form, and elevated $50 \mathrm{~cm}$ above the floor. Two opposing arms are surrounded by $15-\mathrm{cm}-\mathrm{high}$ clear Plexiglas walls (closed arms) while the other arms are devoid of walls (open arms). Mice are placed in the center of the apparatus, facing an open arm, to begin the 5-min test period. All tests were videotaped and then later scored for the various measurements. Latency is defined as time to the first entry into an arm, and an entry is defined as having four paws in an arm of the plus-maze.

Feeding study. Mice were housed individually for at least $3 \mathrm{~d}$ before the beginning of the experiment. Two pellets of food were placed in each lid and were held in place by a small wire mesh bag of marbles. Food pellets were replaced when they weighed $<4 \mathrm{~g}$. Mice and food pellets were weighed within $1 \mathrm{~h}$ of the beginning (6:00) and the end (20:00) of the light period for 5 consecutive days. Cages were examined at each weighing for possible hoarding of food pellets.

Statistical analysis. All statistical analysis was performed with StatView 4.0, using the unpaired $t$ test. Data is presented as mean \pm SE.

\section{Results}

Generation of $\alpha C R H-B P$ transgenic mice. In this study, we generated transgenic mice that constitutively express elevated levels of CRH-BP in their anterior pituitary gland. Because the expression is high in the anterior pituitary, the endocrine site of action of $\mathrm{CRH}$, this tests the role of $\mathrm{CRH}-\mathrm{BP}$ in the modulation of hypothalamic CRH activity. We used the previously characterized pituitary $\alpha$-GSU $4.6-\mathrm{kb}$ promoter linked to the mouse CRH-BP cDNA ( $\alpha$ CRH-BP; Fig. $1 a)$.

To confirm that the $\alpha \mathrm{CRH}-\mathrm{BP}$ construct would generate a secreted, functional product, we tested it in a tissue culture 
a

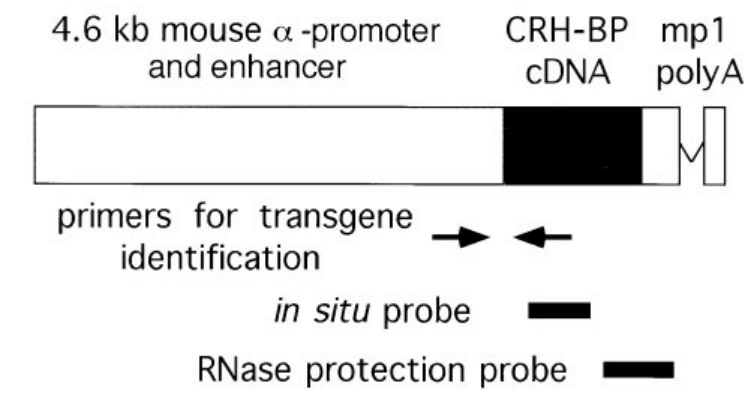

b

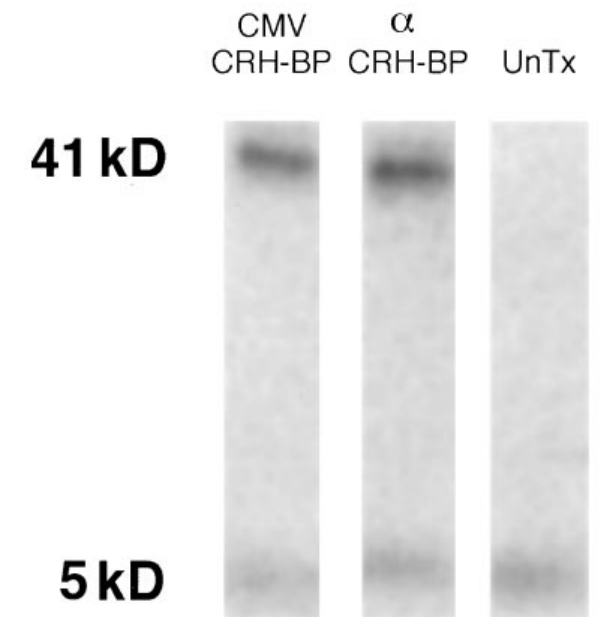

Figure 1. Transgene construct and transfection data. (a) The transgene construct was generated as described in Methods. The promoter consists of $4.6 \mathrm{~kb}$ of the $\alpha$-GSU 5'-flanking region, attached to $1.3 \mathrm{~kb}$ of the mCRH-BP cDNA and $0.5 \mathrm{~kb}$ of the mouse protamine 1 intron and polyadenylation signal. Arrows, PCR primers used to identify transgenic mice. The locations of riboprobes used for in situ hybridization and RNase protection are also indicated. $(b){ }^{125} \mathrm{I}-\mathrm{CRH}$ crosslinking of media from $\alpha$-TSH cells transfected with the $\alpha$ CRH-BP construct or a control CMV-CRH-BP construct demonstrates that the cells secreted functional protein from both constructs. Media from cells transfected with $\alpha \mathrm{CRH}-\mathrm{BP}$ was concentrated 10-fold. UnTx, Untransfected $\alpha$-TSH cells used as a negative control. The cross-linked CRH-CRH-BP complex is $41 \mathrm{kD}$, whereas unbound $\mathrm{CRH}$ is $5 \mathrm{kD}$.

system. We used both $\alpha$-TSH cells, a thyrotrope-like cell line (15), and $\alpha \mathrm{T} 3-1$ cells, which are gonadotrope-like cells (14). The construct was transfected into these cells by $\mathrm{CaPO}_{4}$ precipitation at various concentrations. Both cell extracts and media were assayed for CRH-BP activity by cross-linking to ${ }^{125}$ I-CRH. Both $\alpha$-TSH (Fig. $1 b$ ) and $\alpha$ T3-1 cells (data not shown) were able to make and secrete functional CRH-BP. This verified the integrity of the construct and confirmed that the transgenic CRH-BP was secreted from cells.

The transgene construct was then microinjected into $F_{2}$ zygotes from C57BL $/ 6 \times \mathrm{SJL}$ parents to generate eight transgenic founders. Six lines were produced and used for further analysis.
Transgenic mice have elevated $C R H-B P m R N A$ and protein levels. Animals from each line were killed, and pituitary RNA was collected to determine the relative level of transgene expression in each line. An RNase protection assay capable of simultaneously identifying transgene and endogenous CRH-BP mRNA demonstrated that five transgenic lines were expressing the $\alpha$ CRH-BP transgene. Two of these lines (lines 2 and 6) exhibited transgenic CRH-BP mRNA expression that was elevated significantly above endogenous levels (data not shown). In situ hybridization was used to illustrate that CRH-BP expression is elevated significantly in the transgenic pituitaries in these two lines (Fig. 2, $a$ and $b$, and data not shown). The low level of endogenous CRH-BP expression in corticotropes necessitates that slides be exposed to emulsion for 4-6 wk to detect a clear signal. In contrast, the transgenic pituitaries were enriched sufficiently in CRH-BP transcripts such that the slides required developing after 7-14 $\mathrm{d}$.

To determine if the elevated CRH-BP expression translated to increased protein levels, total pituitary protein was collected and used in a cross-linking assay with ${ }^{125}$ I-CRH. Using equal amounts of protein from transgenic and nontransgenic littermates, most lines had increased cross-linking activity in the transgenic pituitaries. Lines 2 and 6 exhibited the highest amounts of CRH-BP (Fig. $2 c$ ), consistent with the results of the RNase protection and in situ hybridization assays. Thus, in these two lines, transgene mRNA and protein levels are correlated.

Transgenic mice have normal basal corticosterone and ACTH levels and are able to mount an appropriate stress response. Progeny from lines 2 and 6 were analyzed to determine the basal effects of chronic excess pituitary CRH-BP. Plasma was collected by rapid retroorbital phlebotomy and analyzed by corticosterone and ACTH RIA. There was no significant difference in basal corticosterone or ACTH concentrations between transgenic and nontransgenic animals of either sex (Fig. 3, and data not shown). In addition, adrenal tissue from transgenic mice exhibited normal morphology (data not shown).

A restraint stress protocol was used to assess the ability of the transgenic mice to increase serum corticosterone levels in response to stress. Analysis of several control C57BL/6J males indicated that the peak serum corticosterone concentration occurs between 20 and $40 \mathrm{~min}$ after the initiation of stress and that corticosterone returns to basal levels by $80-100 \mathrm{~min}$. In a study of 20 transgenic male mice and their littermates, the transgenic mice exhibited a stress response virtually identical to the nontransgenic mice (Fig. $4 \mathrm{~b}$ ). Corticosterone levels peaked at $343 \pm 23 \mathrm{ng} / \mathrm{ml}$ at $40 \mathrm{~min}$ after the initiation of restraint stress and returned to basal levels by $80 \mathrm{~min}$. Female transgenic mice also demonstrated a normal increase in corticosterone after restraint stress (data not shown).

Analysis of ACTH concentrations during restraint stress indicated that the increase in these levels occurred at $30 \mathrm{~min}$, just slightly before the increase in corticosterone concentration. ACTH levels returned to normal by $80 \mathrm{~min}$. Transgenic mice also showed a normal pattern of ACTH increase (data not shown).

An increase in basal CRH and AVP expression may compensate for the elevated CRH-BP. The normal basal corticosterone and ACTH levels in mice with chronic excess CRH-BP could be explained by the existence of homeostatic mechanisms designed to maintain balance within the HPA axis. For 

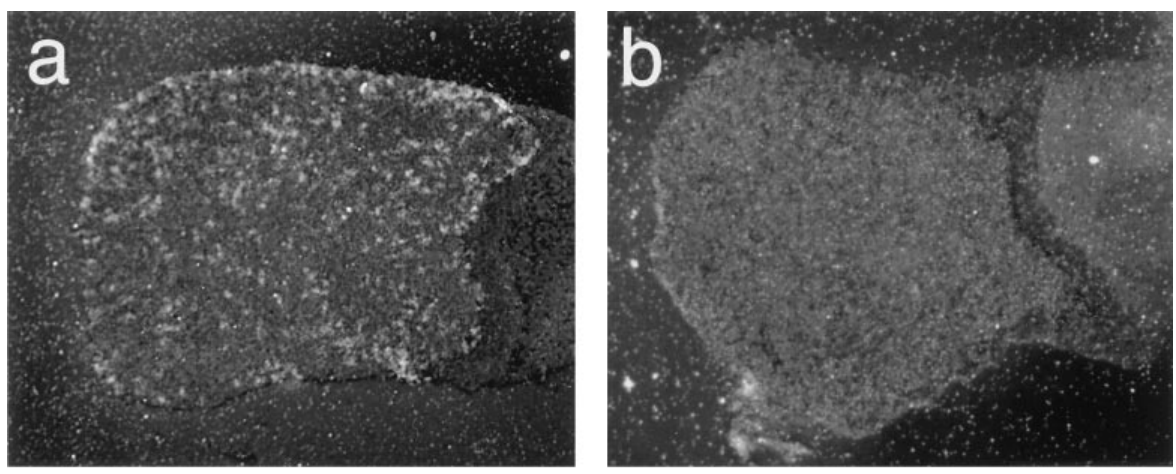

C

line 6

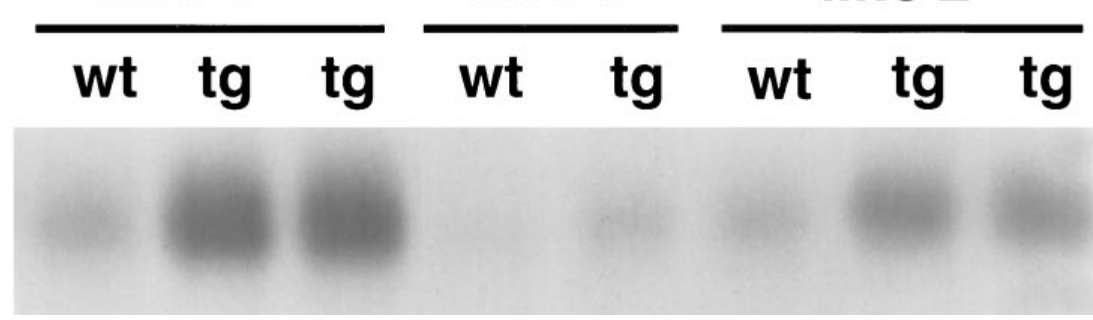

Figure 2. Transgenic mice have increased expression of CRH-BP mRNA and elevated levels of CRH-BP protein. In situ hybridization of pituitaries from a transgenic mouse $(a)$ and its nontransgenic littermate $(b)$ from line 6 demonstrates elevated CRH-BP expression in the transgenic mouse. When the slides were developed, the endogenous CRH-BP transcripts in the nontransgenic pituitary were not yet clearly visible. The pattern of expression in the transgenic pituitary is similar to the normal pattern of thyrotropes and gonadotropes. (c) ${ }^{125} \mathrm{I}$-CRH cross-linking of pituitary protein extracts from transgenic $(\mathrm{tg})$ and nontransgenic $(w t)$ littermates indicates that transgenic mice have higher amounts of CRH-BP activity. Each lane contains an equivalent amount of total protein. example, a compensatory increase in CRH levels could result in a normal level of "free" CRH. Alternatively, an increase in AVP, an ACTH secretagogue that potentiates the activity of CRH (23), could normalize ACTH production. To investigate these possibilities, brain sections from unstressed animals were examined by quantitative in situ hybridization with $\mathrm{CRH}$ and AVP riboprobes. The entire PVN of each brain was sectioned, and alternate sections were examined for CRH and AVP, respectively. Integrated signal intensity was determined by densitometric analysis of autoradiography films. CRH mRNA lev-

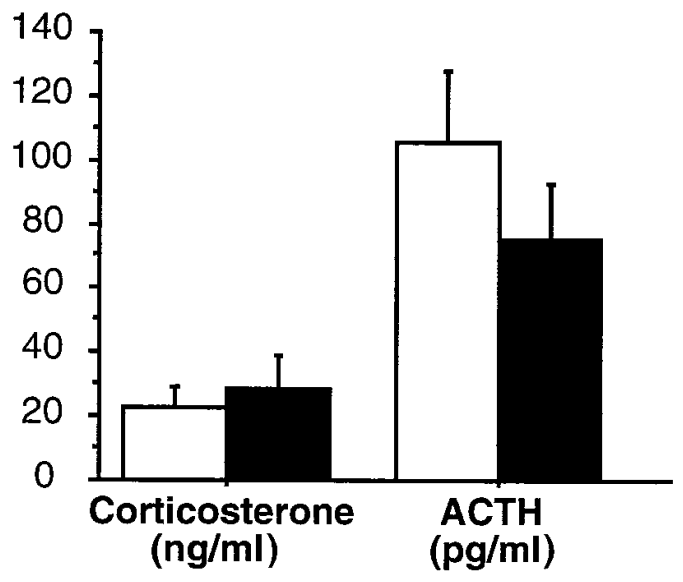

Figure 3. Transgenic mice have normal basal corticosterone and ACTH. Plasma corticosterone and ACTH were assayed in male mice between 10 a.m. and noon ( $n=5$ per genotype, line 6$)$. There is no significant difference between the transgenic and nontransgenic values $(P=0.58$ for corticosterone and $P=0.17$ for ACTH $)$. White bars, Nontransgenic; black bars, transgenic. els were elevated by $82 \%$ in transgenic mice $(P<0.01)$ (Fig. 5 , $a$ and $b)$. This level of increase in CRH expression is similar to the increase observed in previous experiments after adrenalectomy (24). In addition, AVP expression was increased by $35 \%$ $(P<0.05)$ in the transgenic mice (Fig. 5, $b$ and $d)$.

Transgenic mice show increased locomotor activity and $a$ trend to decreased anxiety. To determine the behavioral consequences of chronically elevated $\mathrm{CRH}-\mathrm{BP}$, transgenic mice and their nontransgenic littermates were observed by open field and elevated plus-maze testing. On studies performed between 10:00 and 14:00 $(n=20)$, transgenic males exhibited a significant increase in locomotion and rearing $(P<0.05)$ in open field testing (Fig. 6, $a$ and $b$ ). Consistent with the increased activity in the open field test, the transgenic mice made significantly more total arm entries in the elevated plusmaze $(P<0.05)$ and demonstrated a trend toward decreased latency in entering the first arm after placement on the apparatus (Fig. 6, $d$ and $e$ ) (22). The transgenic mice did not spend a significantly different amount of time in the center of the plusmaze than their nontransgenic littermates $(\mathrm{tg}, 70.4 \pm 5.3 \mathrm{~s}$, and $w t, 73.5 \pm 6.5 \mathrm{~s}, P=0.72)$. In a separate set of experiments performed between 16:00 and 18:00 $(n=10)$, the same trends were observed (data not shown), indicating that the activity of the transgenic mice was elevated at two time points during the day, at the normal trough of $\mathrm{CRH}$ as well as before peak levels.

In addition to the increased activity, the transgenic mice showed a trend toward decreased anxiety as indicated by the increased time spent in the open arms of the elevated plusmaze (Fig. $6 f, P=0.15$ ) (22). This same trend was also observed in the experiments performed at a later time of day.

Transgenic mice demonstrate a dampened circadian rhythm of food intake. Elevated $\mathrm{CRH}$ has been associated with decreased feeding in several studies (25). The increased $\mathrm{CRH}$ 

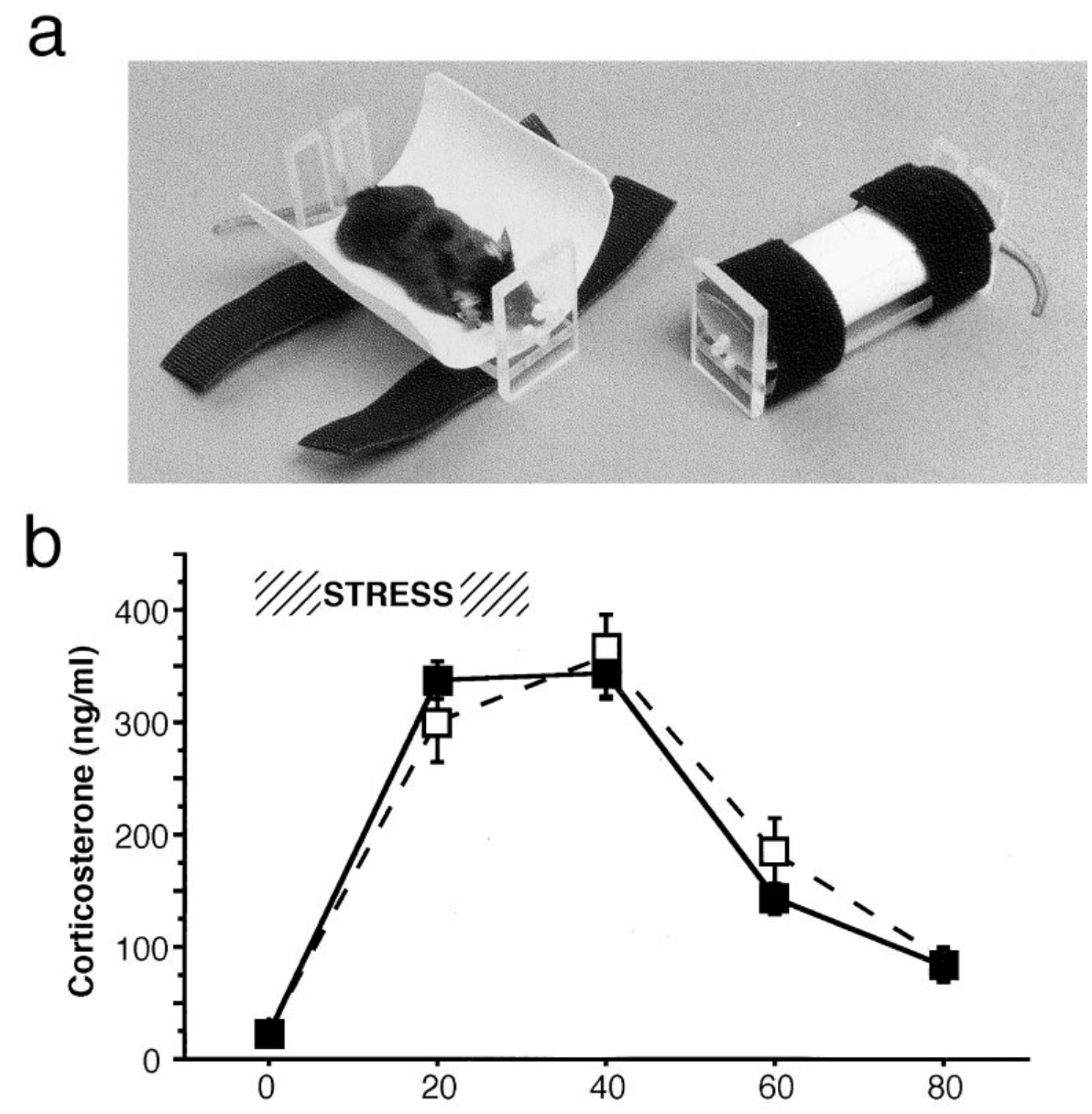

Figure 4. Response of $\alpha \mathrm{CRH}-\mathrm{BP}$ transgenic mice to acute restraint stress. (a) Restraint stress apparatus consists of a Plexiglas platform with an attached piece of Teflon that can be snugly wrapped around mice and held in place with Velcro straps. (b) There is no difference in the corticosterone response to $30 \mathrm{~min}$ of restraint stress of transgenic male mice and their nontransgenic male littermates $(n=4$ per genotype per time point, line 6). $\square$, Nontransgenic; $\mathbf{\square}$, transgenic.

Time (min)

observed in chronic illnesses may lead to many of the associated symptoms, including anorexia and weight loss (11). In addition, dysregulation of the HPA axis has been observed in eating disorders such as anorexia nervosa. According to these models, chronic excess CRH-BP could reduce CRH levels, leading to hyperphagia. However, the elevated CRH observed in apparent compensation for the excess CRH-BP might reduce feeding. Predictions are difficult due to the lack of molecular mechanistic information about the feeding pathway. We observed no obvious differences in the weight of transgenic and wild-type mice of either sex, and a study was performed to measure food consumption.

Transgenic and nontransgenic mice had identical average weights at the start of the experiment $(25.3 \pm 0.5 \mathrm{~g})$. In addition, the mice had virtually identical 24 -h food intake values (transgenic, 3.6 $\pm 0.2 \mathrm{~g}$, and nontransgenic, 3.5 $\pm 0.1 \mathrm{~g}$ ). However, when the values for food intake and changes in mouse weight are separated with respect to the light and dark periods, there is a significant difference in the pattern of feeding for the transgenic mice. The transgenic mice displayed a dampening of the normal light/dark cycle of food intake, eating more during the day and less at night than their littermates (Fig. $7 a$ ). Transgenic mice ate $1.5 \pm 0.1 \mathrm{~g}$ during the day compared with $1.1 \pm 0.1 \mathrm{~g}$ eaten by the wild-type mice $(P<0.001)$. During the night, transgenic mice ate $2.1 \pm 0.2 \mathrm{~g}$, while the wild-type mice ate $2.5 \pm 0.1 \mathrm{~g}(P=0.096)$. Consistent with this eating pattern, the transgenic mice show less fluctuation in their body weight, losing less weight during the day and regaining less at night than the nontransgenic mice (Fig. $7 b$ ).

\section{Discussion}

In this study, we have generated transgenic mice that produce high levels of CRH-BP within the anterior pituitary to study the role that pituitary CRH-BP plays in regulating $\mathrm{CRH}$ activity within the HPA axis. We hypothesize that this elevated CRH-BP will bind to and inactivate $\mathrm{CRH}$ within the anterior pituitary, thereby blocking $\mathrm{CRH}$ receptor activation on corticotropes. The transgenic mice have significantly elevated levels of both CRH-BP mRNA and protein. Despite this increased CRH-BP, these mice are able to maintain normal plasma levels of ACTH and corticosterone. However, both $\mathrm{CRH}$ and AVP expression are elevated significantly in the PVN of the hypothalamus, indicating that both of these hypothalamic factors are involved in maintaining homeostasis in response to the challenge of chronically elevated pituitary $\mathrm{CRH}-$ BP. Restraint stress causes the expected elevation in ACTH and corticosterone, and the kinetics of this response are similar 
a

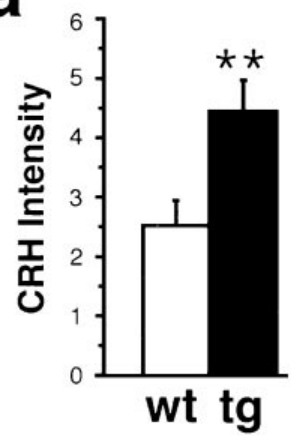

b

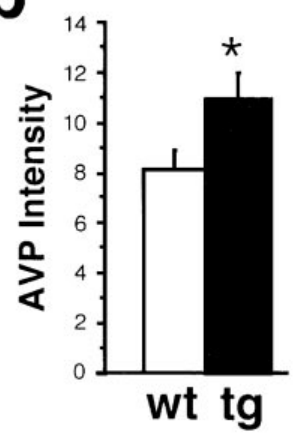

C

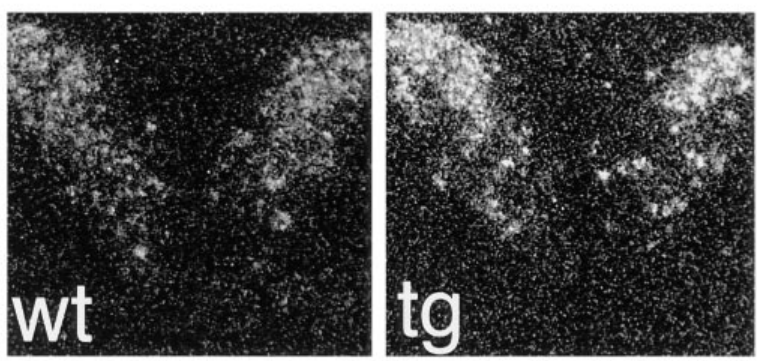

d

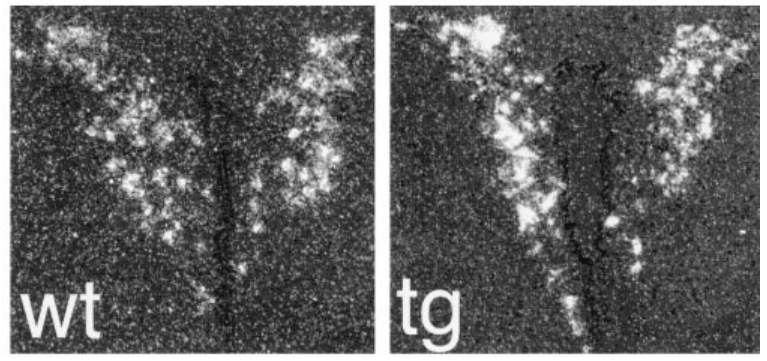

Figure 5. Increased basal CRH and AVP transcripts in transgenic mice may compensate for excess CRH-BP. (a) Average integrated signal intensity of CRH mRNA is increased by $82 \%$ in the PVN of transgenic mice. (b) Representative photomicrographs of slides hybridized for $\mathrm{CRH}$ mRNA illustrate the increased signal present in transgenic brain. (c) AVP mRNA levels are also increased by $35 \%$ in transgenic mice. (d) Representative slides demonstrate this increase in AVP expression. $n=10$ slides per genotype, line 6 ; ${ }^{*} P<0.05$; ** $P<0.01$. White bars, Nontransgenic $(w t)$; black bars, transgenic $(t g)$. to the nontransgenic littermates. In addition, although the HPA axis of these mice appears to be capable of compensation to maintain normal levels of ACTH and corticosterone, they do have behavioral differences from their littermates, demonstrating increased activity and slightly decreased anxiety. The transgenic mice also have an altered feeding pattern. The stimulus for the behavioral alterations could be CRH-BP transgene expression in the brain or could be a side effect of complex compensatory changes.

Homeostatic mechanisms are important for the survival and well-being of all animals. Disruptions of the HPA axis are associated with a variety of disorders in humans, including anorexia nervosa, major depression, Alzheimer's disease, Cushing's syndrome, and some autoimmune disorders $(1,2)$. The HPA axis is tightly regulated to avoid hyper- and hypoactivity, with both glucocorticoids and ACTH acting in negative feedback loops to control appropriate $\mathrm{CRH}$ production (26). In the $\alpha \mathrm{CRH}-\mathrm{BP}$ transgenic mice, the normal ACTH and corticosterone levels along with elevated $\mathrm{CRH}$ and AVP expression demonstrate the ability of the HPA axis to maintain appropriate levels of corticosterone despite the chronic challenge of elevated CRH-BP. The existence of this compensation indicates that the elevated CRH-BP likely initially decreased CRH levels at the corticotropes, but that feedback mechanisms have responded to the excess CRH-BP and stabilized the axis. The increased $\mathrm{CRH}$ and AVP in the CRH-BP transgenic mice support the hypothesis that CRH-BP blunts the effects of $\mathrm{CRH}$ upon the corticotropes. The complexity of the control mechanisms of the HPA axis and the redundancies of the system demonstrate the importance of an intact HPA axis for the animal. The need to maintain homeostasis may explain why the transgenic mice are able to alter their HPA axis to compensate for the chronic elevation of CRH-BP.
The CRH-BP transgenic mice demonstrated significantly increased activity in both the open field test and in the elevated plus-maze. This behavioral phenotype may be due to CRH-BP interactions occurring outside of the HPA axis. Although the $\alpha$-GSU promoter directed reporter transgene expression predominantly in the anterior pituitary, occasional expression was also detected in additional brain regions of some transgenic lines, including the lateral septal nucleus (LS) (12). Thus, it is possible that CRH-BP levels may be increased in the LS of the $\alpha \mathrm{CRH}-\mathrm{BP}$ mice. $\mathrm{CRH}$ is also present in the LS, where it may be involved in regulating locomotor activity $(27,28)$, and $\mathrm{CRH}$ injected intracerebroventricularly has been shown to cause decreased locomotion in mice (29). Thus, the increased locomotor activity in the transgenic mice may be due to alterations in CRH activity in the LS of transgenic mice.

An alternative explanation for the increased activity observed in the $\alpha \mathrm{CRH}-\mathrm{BP}$ mice may be that the normal circadian rhythmicity of the transgenic mice has been disturbed. Increased activity of the transgenic mice during the day and decreased activity at night could also result in the dampened fluctuation seen in food intake. The homeostatic mechanisms that are compensating for the excess CRH-BP may be able to regulate a certain level of corticosterone without being able to generate an appropriate rhythm. That $\mathrm{CRH}$ knockout mice have a normal circadian rhythm of locomotor activity despite a lack of glucocorticoid rhythmicity $(30,31)$ may argue against this possibility. While the mechanism cannot be predicted at this time, altered gene expression in the brain in response to chronically elevated CRH-BP could have triggered some of the behavioral changes as an unwelcome side effect.

$\mathrm{CRH}$ has been shown to have a potent anxiogenic effect when administered centrally $(29,32)$. Based on these results, the $\alpha \mathrm{CRH}-\mathrm{BP}$ mice might be expected to demonstrate a 

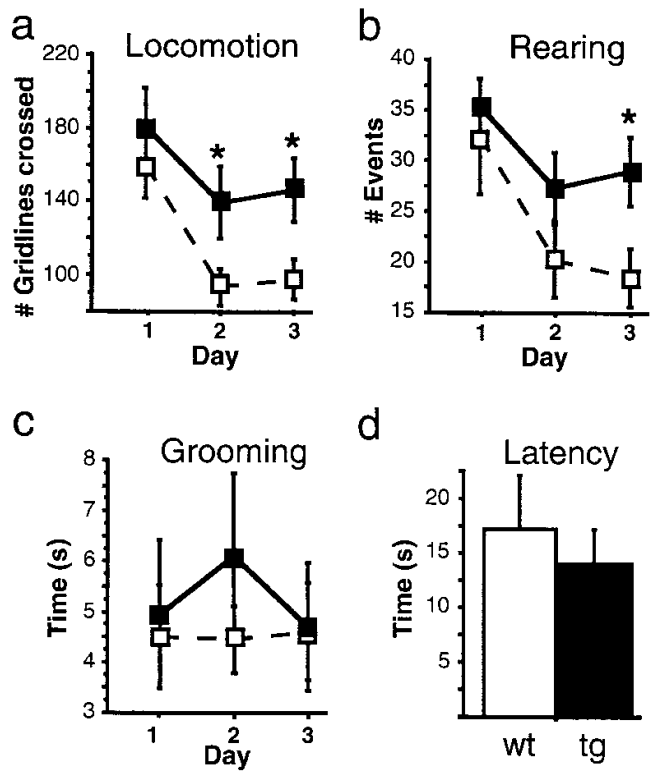

d
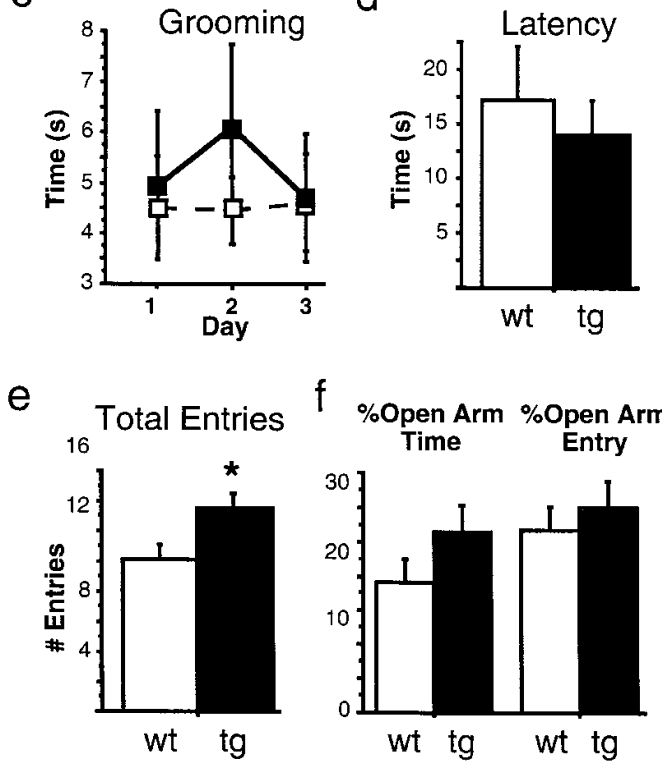

Figure 6. Behavioral analysis of transgenic mice. (a) Mean locomotor activity, $(b)$ rearing, and $(c)$ grooming time of transgenic and nontransgenic male mice assayed for 5 min each day for 3 consecutive days. Transgenic mice demonstrate increased locomotor activity on days 2 and 3. In addition, rearing counts are elevated for transgenic mice on day 3. $(d-f)$ Data from elevated plus-maze indicate that transgenic mice have increased total arm entries and a tendency to spend more time in the open arms of the maze. $n=20$ per genotype, line 6 ; $* P<0.05$. $\square$, nontransgenic $(w t) ; \square$, transgenic $(\operatorname{tg})$.

decrease in anxiety. The elevated plus-maze showed a tendency towards anxiolysis in the transgenic mice. Again, the transgene directed elevated CRH-BP in the anterior pituitary, but anxiogenic effects could result from lower levels of transgene expression in some brain nuclei (12).

These transgenic mice studies have shown that CRH-BP can function within the HPA axis, and that chronic overexpression of pituitary CRH-BP leads to compensatory changes in PVN expression of CRH and AVP. This supports the hypothesis that $\mathrm{CRH}-\mathrm{BP}$ functions in the anterior pituitary to modulate the effects of $\mathrm{CRH}$ on the corticotropes. The complexity of multifactoral checks and balances in the HPA axis revealed in the $\mathrm{CRH}$-deficient knockout mice (30) was also demonstrated in the CRH-BP transgenic mice, where the HPA axis responded to correct the effects of the excess CRHBP. It is plausible that HPA axis set-points are firmly established and that chronic administration of CRH-BP, if feasible, would not be efficient in maintaining a new set-point. Nevertheless, the molecular mechanisms regulating $\mathrm{CRH}-\mathrm{BP}$ could

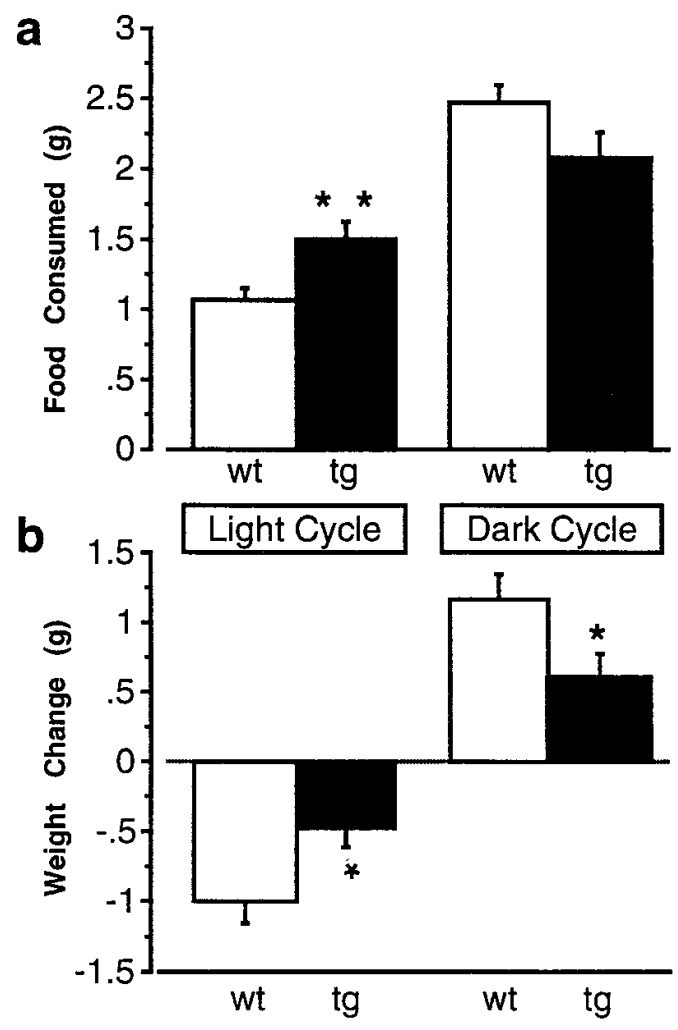

Figure 7. Diurnal pattern of food consumption. (a) Transgenic male mice ate more food during the light period and less food during the dark period than their littermates. (b) The weight of the transgenic mice changed less with the light-dark period than the nontransgenic littermates. ( $n=12$, transgenic, and $n=14$, nontransgenic, line 6). $* P<0.05 ; * * P<0.01 ;$ white bars, nontransgenic $(w t)$; black bars, transgenic $(\operatorname{tg})$.

be dysfunctional in various disorders of the HPA axis. The behavioral changes displayed by the transgenic mice suggest the importance of investigating the role of $\mathrm{CRH}-\mathrm{BP}$ in the brain. Further studies to investigate the altered circadian rhythm of the transgenic mice may also reveal interesting interactions between the HPA axis and rhythmicity.

\section{Acknowledgments}

We would like to thank Thom Saunders of the University of Michigan transgenic animal model core for training in the production of transgenic mice (http://www.med.umich.edu/tamc/), and Jill Karolyi for maintaining and managing the Department of Human Genetics animal colony.

This work was supported by a Young Investigator Award from the National Alliance for Research on Schizophrenia and Depression (to A.F. Seasholtz) and by National Institutes of Health grants R01MH-49463 (to S.A. Camper), R01-DK-42730 (to A.F. Seasholtz), and T32 GM-07863 (to H.L. Burrows), a University of Michigan Presidential Initiatives Fellowship in Organogenesis (to H.L. Burrows), and a University of Michigan Rackham Association of Fellows fellowship (to H.L. Burrows).

\section{References}

1. Tsigos, C., and G.P. Chrousos. 1994. Physiology of the hypothalamic-pituitary-adrenal axis in health and dysregulation in psychiatric and autoimmune 
disorders. Endocrinol. Metab. Clin. North Am. 23:451-467.

2. Sapolsky, R.M., L.C. Krey, and B.S. McEwen. 1986. The neuroendocrinology of stress and aging: the glucocorticoid hypothesis. Endocr. Rev. 7:284301.

3. Sasaki, A., A.S. Liotta, M.M. Luckey, A.N. Margioris, T. Suda, and D.T. Kreiger. 1984. Immunoreactive corticotropin releasing factor is present in human maternal plasma during the third trimester of pregnancy. J. Clin. Endocrinol. Metab. 59:812-814.

4. Suda, T., M. Iwashita, F. Tozawa, T. Ushiyama, N. Tomori, T. Sumitomo, Y. Nakagami, H. Demura, and K. Shizume. 1988. Characterization of CRH binding protein in human plasma by chemical crosslinking and its binding during pregnancy. J. Clin. Endocrinol. Metab. 67:1278-1283.

5. Petraglia, F., E. Potter, V.A. Cameron, S. Sutton, D.P. Behan, R.J. Woods, P.E. Sawchenko, P.J. Lowrey, and W. Vale. 1993. Corticotropin-releasing factor-binding protein is produced by human placenta and intrauterine tissues. J. Clin. Endocrinol. Metab. 77:919-924.

6. Linton, E.A., C.D.A. Wolfe, D.P. Behan, and P.J. Lowrey. 1988. A specific carrier substance for human corticotropin releasing factor in late gestational maternal plasma which could mask the ACTH-releasing activity. Clin. Endocrinol. 28:315-324.

7. Potter, E., D.P. Behan, E.A. Linton, P.J. Lowrey, P.E. Sawchenko, and W.W. Vale. 1992. The central distribution of a corticotropin-releasing factor (CRF)-binding protein predicts multiple sites and modes of interaction with CRF. Proc. Natl. Acad. Sci. USA. 89:4192-4196.

8. Cortright, D.N., A. Nicoletti, and A.F. Seasholtz. 1995. Molecular and biochemical characterization of the mouse brain corticotropin-releasing hormone-binding protein. Mol. Cell. Endocrinol. 111:147-157.

9. Potter, E., D.P. Behan, W.H. Fischer, E.A. Linton, P.J. Lowrey, and W.W. Vale. 1991. Cloning and characterization of the cDNAs for human and rat corticotropin-releasing factor-binding proteins. Nature. 349:423-426.

10. Oh, Y., H.L. Muller, E.K. Neely, G. Lamson, and R.G. Rosenfeld. 1993. New concepts in insulin-like growth factor receptor physiology. Growth Regul. 3:113-123.

11. Chrousos, G.P. 1992. Regulation and dysregulation of the hypothalamic-pituitary-adrenal axis. The corticotropin-releasing hormone perspective. Endocrinol. Metab. Clin. North Am. 21:833-858.

12. Kendall, S.K., D.F. Gordon, T.S. Birkmeier, D. Petrey, V.D. Sarapura, K.S. O'Shea, W.M. Wood, R.V. Lloyd, E.C. Ridgway, and S.A. Camper. 1994. Enhancer-mediated high level expression of mouse pituitary glycoprotein hormone $\alpha$-subunit transgene in thyrotropes, gonadotropes, and developing pituitary gland. Mol. Endocrinol. 8:1420-1433.

13. Burrows, H.L., T.S. Birkmeier, A.F. Seasholtz, and S.A. Camper. 1996. Targeted ablation of cells in the pituitary primordia of transgenic mice. Mol. Endocrinol. 10:1467-1477.

14. Windle, J.J., R.I. Weiner, and P.L. Mellon. 1990. Cell lines of the pituitary gonadotrope lineage derived by targeted oncogenesis in transgenic mice. Mol. Endocrinol. 4:597-603.

15. Akerblom, I.E., E.C. Ridgway, and P.L. Mellon. 1990. An $\alpha$-subunitsecreting cell line derived from a mouse thyrotrope tumor. Mol. Endocrinol. 4: $589-596$

16. Hogan, B., R. Beddington, F. Constantini, and E. Lacey. 1994. Manipulating the Mouse Embryo: A Laboratory Manual. Cold Spring Harbor Labora- tory Press, Plainview, New York. $457 \mathrm{pp}$

17. Tuli, J.S., J.A. Smith, and D.B. Morton. 1994. Corticosterone, adrenal and spleen weight in mice after tail bleeding, and its effect on nearby mice. $L a b$. Anim. 29:90-95.

18. Herman, J.P., S.J. Weigand, and S.J. Watson. 1990. Regulation of basal corticotropin-releasing hormone and arginine vasopressin messenger ribonucleic acid expression in the paraventricular nucleus: effects of selective hypothalamic deafferentations. Endocrinology. 127:2408-2417.

19. Seasholtz, A., F. Bourbonais, C. Harnden, and S. Camper. 1991. Nucleotide sequence and expression of the mouse corticotropin-releasing hormone gene. Mol. Cell. Neurosci. 2:266-273.

20. Herman, J.P. 1995. In situ hybridization analysis of vasopressin gene transcription in the paraventricular and supraoptic nuclei of the rat: regulation by stress and glucocorticoids. J. Comp. Neurol. 363:15-27.

21. Nakajima, M., A. Inui, A. Asakawa, K. Momose, N. Ueno, A. Teranishi, S. Baba, and M. Kasuga. 1998. Neuropeptide Y produces anxiety via Y2-type receptors. Peptides (Tarryt.). In press.

22. Lister, R.G. 1987. The use of a plus-maze to measure anxiety in the mouse. Psychopharmacology. 92:180-185.

23. Gillies, G.E., E.A. Linton, and P.J. Lowry. 1982. Corticotropin releasing activity of the new CRF is potentiated several times by vasopressin. Nature. 299:355-357.

24. Young III, W.S., E. Mezey, and R.E. Siegal. 1986. Quantitative in situ hybridization reveals increased levels of corticotropin-releasing factor mRNA after adrenalectomy in rats. Neurosci. Lett. 70:198-203.

25. Glowa, J.R., J.E. Barrett, J. Russell, and P.W. Gold. 1992. Effects of corticotropin releasing hormone on appetitive behaviors. Peptides (Tarryt.). 13: 609-621.

26. Dallman, M.F., S.F. Akana, N. Levin, C.-D. Walker, M.J. Bradbury, S. Suemaru, and K.S. Scribner. 1994. Corticosteroids and the control of function in the hypothalamic-pituitary-adrenal (HPA) axis. Ann. NY Acad. Sci. 746:2231 .

27. Swanson, L.W., P.E. Sawchenko, J. Rivier, and W. Vale. 1983. Organization of ovine corticotropin-releasing factor immunoreactive cells and fibers in the rat brain: an immunohistochemical study. Neuroendocrinology. 36:165-186.

28. Lee, E.H.Y., Y.P. Lin, and T.H. Yin. 1988. Effects of lateral and medial septal lesions on various activity and reactivity measures in rats. Physiol. Behav. 42:97-102.

29. Dunn, A.J., and C.W. Berridge. 1990. Physiological and behavioral response to corticotropin-releasing factor administration: is CRF a mediator of anxiety or stress responses? Brain Res. Brain Res. Rev. 15:71-100.

30. Muglia, L.J., L. Jacobson, P. Dikkes, and J.A. Majzoub. 1995. Corticotropin-releasing hormone deficiency reveals fetal but not adult glucocorticoid need. Nature. 373:427-432.

31. Muglia, L.J., L. Jacobson, S.C. Weninger, C.E. Luedke, D.S. Bae, K.-H Jeong, and J.A. Mazjoub. 1997. Impaired diurnal adrenal rhythmicity restored by constant infusion of corticotropin-releasing hormone in corticotropin-releasing hormone-deficient mice. J. Clin. Invest. 99:2923-2929.

32. File, S.E., A.L. Johnston, and H.A. Baldwin. 1988. Anxiolytic and anxiogenic drugs: changes in behavior and endocrine responses. Stress Med. 4:221230 